\title{
$\operatorname{arCOS} D E S I G N$
}

\section{Design Anthropology para muitos mundos possíveis}

Bibiana Serpa (ESDI/UERJ, Brasil)

bibianaoserpa@gmail.com

Mariana Costard (ESDI/UERJ, Brasil)

marianacostard@gmail.com

Instituição: Escola Superior de Desenho Industrial, Universidade Estadual do Rio de Janeiro (ESDI/UERJ)

Endereço: Rua do Passeio, 80 - Centro - Rio de Janeiro 


\title{
Design Anthropology para muitos mundos possíveis
}

Resumo: A partir da nossa perspectiva, situada no Laboratório de Design e Antropologia (LaDA/Esdi/Uerj), apontamos para contribuições teóricas e experiências acadêmicas práticas de uma abordagem interdisciplinar para se pensar um design para muitos mundos possíveis. Partimos de uma perspectiva do sul global (Escobar, 2017) para inspirar uma reorientação ontológica do design, que vá além da lógica dual necessária à manutenção e expansão de formas hegemônicas de conhecimento, e caminhe para um design relacional, autônomo e pluriverso. Buscamos conceitos relevantes da antropologia para "reativar" (Stengers, 2017) outros modos de vida, percebendo essa relação com o outro como caminho possível na tentativa de descolonizar o pensamento, a ciência, o design. Posicionamos design anthropology como uma abordagem que contribui com esse processo na medida em que busca uma outra compreensão das diferenças, abrindo espaço para o dissenso e a democracia. Situamos as nossas pesquisas nesse campo do design e apresentamos aqui parte delas, fortalecendo nosso ensejo por uma outra forma de estar e pensar o mundo.

Palavras-chave: design anthropology, descolonização, pesquisa prática

\section{Design anthropology for many possible worlds}

\begin{abstract}
From our perspective situated in the Laboratory of Design and Anthropology (LaDA/Esdi/Uerj), we point to theoretical contributions and practical academic experiences from an interdisciplinary approach into thinking design for many possible worlds. We start from a global southern perspective (Escobar, 2017) to inspire an ontological reorientation of design that goes beyond the dual logic necessary for the maintenance and expansion of hegemonic forms of knowledge and to move towards a relational, autonomous and pluriverse design. We seek relevant anthropological concepts to "reactivate" (Stengers, 2017) other ways of life, perceiving the relationship with others as a possible way in the attempt to decolonize thought, science, and design. We locate design anthropology as an approach that contributes to this process as it seeks a further understanding of differences by opening space for dissent and democracy. We place our researches in this field of design and present part of them, strengthening our desire for another way of being and thinking the world.
\end{abstract}

Keywords: design anthropology, decolonizing, practical research 


\section{Introdução: design para o pluriverso, uma perspectiva do sul global}

Em "O Bem Viver - Uma oportunidade para imaginar outros mundos", o equatoriano Alberto Acosta (2016) apresenta o conceito de bem viver como alternativa ao desenvolvimento e progresso capitalistas que esbarram hoje em limites ecológicos evidentes. Incorporado como Direitos da Natureza na Constituição do Equador, o Buen Vivir parte de visões de mundo ancestrais de povos indígenas para uma proposição de utopia e quebra de paradigma como uma prática em construção, rumo à comunhão entre a humanidade e a natureza e à construção de sociedades solidárias e sustentáveis. Não pretende um retorno ao passado, mas construir futuros comuns e verdadeiramente democráticos, nos quais há valorização das diversidades culturais e diferentes saberes se juntam, influenciando debates globais sobre outros mundos possíveis.

Inspirado por essa noção e também pelo enunciado zapatista "Queremos um mundo em que caibam muitos mundos" (Movimento Zapatista apud Escobar, 2017) - Arturo Escobar tenta "recuperar o design para a construção de outros mundos" a partir da consciência de sua historicidade e "formação onto-epistêmica patriarcal, capitalista e moderna" (Escobar, 2016, p. 43), formulando as noções de design ontológico e design autônomo como contributos situados da América Latina para a discussão global sobre design contemporâneo, seus desafios e esforços colaborativos recentes.

Em "Autonomía y diseño: La realización de lo comunal" (2017), Escobar afirma que vivemos uma crise de modelo civilizatório da modernidade capitalista ocidental para além de seu modelo econômico neoliberal, mas, também, de suas formas de vida e criação de mundos. Neste livro, o autor observa que muitos grupos sociais têm se empenhado nesse processo de mudança e em defesa de seus lugares, territórios e modos de vida. Diante dos questionamentos a respeito da prática do design face a este cenário, Escobar reconhece que há um importante papel a ser desempenhado pelos designers por meio de abordagens que busquem contribuir para as profundas transições culturais e ecológicas necessárias para enfrentar as crises do clima, dos alimentos, da energia, da pobreza e dos significados - as quais ele nomeia de "design para transições".

Para orientar essas transições, Escobar reforça a importância da consciência histórica sobre o surgimento do design, associado às ideias de desenvolvimento e progresso, a um entendimento ocidental de mundo que inferioriza e torna invisível a diferença e os conhecimentos subalternos, a partir de parâmetros de produtividade e eficiência da visão monocultural da economia de mercado - "sociologia das ausências". Situado nesse modo 
dominante de ver o mundo, ele defende a reorientação do design de uma tradição hegemônica racionalista e dualista para outra relacional, conectada com as transformações da vida; da rejeição de um cartesianismo de um mundo feito de um só mundo, a uma ontologia em que os humanos não descobrem um mundo, mas o constituem, não como objetos, mas como sujeitos autônomos.

Para isso, Escobar propõe um "design ontológico", no sentido de que desenhamos o mundo e formas de ser a partir das ferramentas que criamos, da mesma forma que somos desenhados por elas. Há uma circularidade nesse enfoque ontológico do design, que se situa entre o entendimento e a criação e está relacionado à produção do ser humano e do mundo, às formas como vivemos nossas vidas e nossos entendimentos de mundo, às tradições e categorias que embasam nossos modos de ser. Enquanto designers, entendemos o mundo a partir dos embasamentos em que fomos formados; mas, também, criamos ferramentas e tecnologias que abrem novas possibilidades de ser e viver, que desenham as condições da nossa existência e podem afetar as nossas próprias noções de mundo. Dessa forma, o design ontológico tem necessariamente um caráter crítico e carrega um potencial radical de inovação, na medida em que envolve repensar como está organizada a sociedade, seus valores e modelos, assim como pretende superar as formas de operar convencionais que estão destruindo o planeta.

Escobar vai além dessa perspectiva crítica do design para uma mais propositiva de direcionamento para um "design autônomo", que é relacional e está engajado com as lutas sociais de comunidades em defesa de sua autonomia, seus territórios e mundos-vida. Tem como objetivo a realização do "comunal" enquanto criação para as condições da autocriação contínua da própria comunidade, em que o design entra como ferramenta para reimaginar e reconstruir mundos locais, entendendo que toda comunidade pratica o desenho de si mesma e de seu próprio saber, de modo que os designers são co-investigadores num sistema de investigação próprio, já existente. Acolhe tanto a ancestralidade como a construção de futuros comuns; privilegia formas de organização não patriarcais, não liberais, não centradas no Estado e não capitalistas; pensa seriamente em formas de habitar o planeta em comunhão com a natureza.

Inspiradas por essas perspectivas do sul global - nas quais nos incluímos - para repensar o design e os modos de estar no mundo, neste artigo articulamos referências importantes da antropologia que nos ajudam a ultrapassar a lógica hegemônica e ocidental de conhecimento e contribuir para uma descolonização da ciência e do design, associando essas reflexões também à nossa prática acadêmica. Aproximamos os aprendizados da 
antropologia da nossa própria atividade enquanto designers, explorando o conceito e ação do campo em formação design anthropology. Situadas no Laboratório de Design e Antropologia (LaDA/Esdi/Uerj), buscamos nos engajar com os contextos e as pessoas com quem trabalhamos, atuando em correspondência a seus fluxos e relações, num processo aberto de investigação colaborativa a partir da abordagem deste campo emergente e interdisciplinar.

\section{Perspectiva antropológica para reativar outros saberes}

Da nossa prática acadêmica interdisciplinar, trazemos aqui alguns conceitos e reflexões da antropologia e disciplinas em diálogo para subsidiar essa reflexão ontológica de uma perspectiva mais plural de constituição e formação de mundos, de modo a cultivar uma "atenção imanente" (Stengers, 2017) na tentativa de descolonizar o pensamento, a ciência e o design.

No texto "Reativar o animismo", a filósofa belga Isabelle Stengers (2017) propõe uma prática situada que convide à participação, buscando criar pontes e tecer relações, e deixando que ideias do passado afetem as construções presentes. Evoca o animismo para confrontar uma Ciência ${ }^{1}$ voltada à conquista do mundo, que serviu para justificar a colonização e a categorização que ainda persiste hoje, através de um pensamento racional e dualista que tem o poder de validar ou não os conhecimentos que podem existir. Ao colocar o animismo em uma categoria "sobrenatural" e, portanto, não explicável pela Ciência, ela determina sua não existência enquanto verdade. Stengers defende uma ciência aventureira, baseada em experimentos que questionem as próprias perguntas e possibilitem a criação de novas perguntas. Uma forma de fazer ciência que se coloque em risco ao posicionar também seu modo hegemônico de pensamento; uma ciência rizomática, que conecte práticas, e modos heterogêneos de vida, sem privilégios e passíveis de outras conexões. Reativar (to reclaim) o animismo

1 Distinção da própria Isabelle Stengers (2017): "A Ciência, quando considerada no singular e com "C" maiúsculo, pode de fato ser descrita como uma conquista generalizada propensa a traduzir tudo o que existe em conhecimento racional, objetivo. Em nome da Ciência, um julgamento foi atribuído à vida de outros povos, e esse julgamento também prejudicou gravemente nossas relações com nós mesmos sejamos nós filósofos, teólogos ou senhoras idosas com seus gatos. As realizações científicas, por outro lado, exigem pensar em termos de uma "aventura das ciências" (no plural e com "c" minúsculo). É certamente difícil distinguir entre essa aventura e a Ciência como uma conquista generalizada se considerarmos o que é feito em nome da ciência hoje. No entanto, é importante estabelecer essa distinção, pois ela dá vazão a uma nova perspectiva: aquilo a que se chama Ciência, ou a ideia de uma racionalidade científica hegemônica, pode ser entendido em si mesmo como produto de um processo de colonização". 
não significa retomar algo que foi perdido, mas reivindicar, recuperar, curar, lutar, aprender o necessário para habitar; uma "ligação entre magia e espiritualidade e transformação social e política" (Stengers, 2017, p. 8).

Ao cultivar "a arte da atenção imanente" (Stengers, 2017, p. 12), desafiamos criticamente o nosso apego à verdade e tentamos "resistir a um poder colonizador", contribuindo para a tentativa de uma "descolonização do pensamento" (Viveiros de Castro apud Stengers, 2017, p. 3), aplicada ao entendimento de ciência e mesmo do design, a partir do sentir o outro.

Para isso, recorremos ao artigo "O nativo relativo" de Viveiros de Castro (2002), em que o autor analisa as regras do jogo antropológico para entender o conhecimento gerado na relação social entre o observador e o 'nativo', seus discursos enquanto práticas de sentido e as transformações relacionais decorrentes. Entende que a antropologia deve recusar a vantagem estratégica do discurso do antropólogo numa relação unilateral e reivindicar uma igualdade de direito entre os sujeitos dos discursos, o que vai além de assumir o 'nativo' como sujeito ao invés de objeto. O antropólogo que parte de um conhecimento pré-definido do 'nativo' circunscreve os mundos possíveis expressos por esse outrem e impede sua capacidade de alteração. $\mathrm{O}$ objeto da antropologia seria, então, a variação das relações sociais, e seu propósito não deve ser explicar, nem interpretar, mas multiplicar e experimentar; verificar os efeitos que o pensamento nativo produz sobre o nosso pensamento.

Segundo Viveiros de Castro, Roy Wagner (2017) foi um dos primeiros antropólogos a constatar essa relação entre culturas, sob os conceitos de objetividade relativa (consciente dos seus pressupostos culturais) e de relatividade cultural (equivalência entre diferentes culturas), em que "a apreensão de uma cultura envolve a ideia de relacionamento entre duas variedades do fenômeno humano" (p. 129), noção mais apropriada do que a de exame ou análise (Wagner apud Viveiros de Castro, 2002). Não se trata, entretanto, de uma relatividade do verdadeiro, mas da verdade do relativo, que é a relação; o que Deleuze chama de perspectivismo (Viveiros de Castro, 2002).

Marilyn Strathern (2006) se aproxima do entendimento de Wagner e Viveiros de Castro e entende a antropologia como uma prática de conhecimento que estuda relações com relações, que se coloca em risco na relação com mundos inesperados. O eixo nós-eles (pesquisador-'nativo'), segundo ela, é uma "tentativa deliberada de conseguir vislumbrar um diálogo interno nos limites das próprias linguagens" (Strathern, 2006, p. 29). Não se trata de conceber que é viável substituir conceitos e entendimentos exógenos por correspondentes nativos, mas, sim, transmitir a complexidade dos 
conceitos e entendimentos nativos com referência ao contexto particular em que são produzidos.

Ao introduzir uma perspectiva de gênero na sua pesquisa, a antropóloga reconhece a estrutura do saber feminista próxima à da ciência social, no qual pontos de vista coexistem não com objetivo de substituir uns aos outros, mas de manter um projeto aberto, sem fim. A autora entende que, tanto internamente quanto externamente, o pensamento feminista vive em disputa. A base destes múltiplos debates internos gerados no âmbito do conhecimento feminista viria da competitividade das suas próprias abordagens internas, somadas à abertura interdisciplinar deste saber. Essas vertentes não se juntam como um todo mas são presenças na discussão. É um conflito perpétuo. As diferenças de experiências resultam em divergências teóricas que, por sua vez, constituem, em seu conjunto, um discurso. Da mesma forma, o feminismo se coloca como outrem à situação hegemônica (capitalista, racionalista e patriarcal). Ou seja, "feminismo situa-se no próprio debate" (Strathern, 2006, p. 56).

Essa outra maneira de organizar o saber, a partir do conflito plural e não dual, desafia o modo pelo qual a ciência conhece e reproduz a verdade, como já vimos em Stengers (2017). Essa perspectiva crítica reconhece que tudo é construído, em contraste com as questões postas como "naturais" e, dessa forma, pode-se inferir que "se tudo é construído, nada é inevitável" (Strathern, 2006, p. 69).

Ao questionar a naturalidade das estruturas, uma abordagem feminista do pensar e do fazer ciência pode ser compreendida em um antagonismo da interação homem-mulher reduzida às preocupações das mulheres exclusivamente. Não surpreendentemente os estudos ditos feministas colocam as mulheres não como as proponentes intencionais de novas formas de ver e pensar o mundo, mas como objetos de estudo, como se às suas opressões fossem conferidas notas de exotismo dignas de análise. O que propomos não se relaciona com isso. Com o apoio de Strathern (2006), compreendemos que as instituições dominantes e suas relações de poder desencadeiam interesses específicos na vida social, portanto o que está em jogo é a interpretação dessa vivência, o que está em disputa é a narrativa, a visão de mundo. O entendimento deste mundo, sempre parcial e aberto, permanece ingênuo a menos que se questione a ideologia destes interesses. Ou, como elucida o pensamento de Strathern complementado por Donna Haraway: "importam que ideias usamos para pensar (com) outras ideias, importam quais histórias contamos para contar outras histórias" (Strathern apud Haraway, 2016, p.7). 
Nesse sentido, Haraway também nos ajuda a pensar esses outros modos de vida, de saberes e de mundos, a partir da escuta, do fazer-com e da contação de outras histórias e narrativas possíveis. Utiliza o conceito de simpoiesis para se referir a esse fazer-com entre seres multiespécies, à intimidade entre estranhos ao fazer parentescos horizontais. Para a filósofa, as criaturas não precedem suas relações, elas se fazem através da involução do material semiótico. E, nesse emaranhado relacional, as contradições, mesmo que dialéticas, não se resolvem em pretensas totalidades: a unidade, de alguma maneira, tem a ver com a "tensão de manter juntas coisas incompatíveis porque todas são necessárias e verdadeiras" (Haraway, 2009: 35).

Tratando como reais todas as narrativas e contradições, Haraway nos empurra de volta à atenção imanente de Stengers (2017), que, no ensejo de praticar uma descolonização do pensamento, nos propõe um fazer crítico a partir de tudo que aprendemos e que somos. As categorias em que nos incluímos são complexas e construtos das práticas sociais onde estamos inseridos e do juízo que fazemos delas. A consciência de classe, raça, gênero, do sul global é consequência, como aponta Haraway (2009), das realidades sociais contraditórias do capitalismo, do colonialismo e do patriarcado. Os dualismos insistentes aos quais sempre fomos expostas nos colocam em um papel crítico frente à lógica e prática de dominação sobre trabalhadores, negros, indígenas, mulheres, fauna e flora, ou sobre "todos aqueles que foram constituídos como outros e cuja tarefa consiste em espelhar o eu [dominante]" (Haraway, 2009, p 90). A respeito da dialética relação entre esse outro e esse eu, a autora complementa:

\begin{abstract}
O eu é o Um que não é dominado, que sabe isso por meio do trabalho do outro; o outro é o um que carrega o futuro, que sabe isso por meio da experiência da dominação, a qual desmente a autonomia do eu. Ser o Um é ser autônomo, ser poderoso, ser Deus; mas ser o Um é ser uma ilusão e, assim, estar envolvido numa dialética de apocalipse com o outro. Por outro lado, ser o outro é ser múltiplo, sem fronteira clara, borrado, insubstancial (Ibidem, p. 91).
\end{abstract}

Ao pontuar essas ideias do outro e do eu, da fluidez do outro em relação ao eu e da dominação necessária ao eu em relação ao outro para se reconhecer como ser dominante, Donna Haraway expressa seu sentimento ciborguiano $^{2}$, que é ao mesmo tempo libertador e potente. Para ela, é

2 Em "Manifesto Ciborgue: Ciência, tecnologia e feminismo-socialista no final do século XX", Haraway apresenta o conceito de ciborgue como como metáfora para a crítica da identidade em favor das diferenças e para reivindicar uma imagem condensada das transformações sociais e políticas do Ocidente na virada do século. 
importante incorporar o processo de dominação e vislumbrar novas possibilidades de ação e reflexão.

A colocação de Haraway propõe de forma muito simplificada a incorporação das vivências de dominação pelo simples fato de compreendêlas e estar ciente e sensível a elas. Ao contrário da autora, entendemos que há, sim, uma leitura privilegiada do mundo. Não porque acreditamos que os dominantes sejam, em juízo, melhores, mas porque gozam da aceitação discursiva desta leitura, que é majoritariamente branca, norte-globalista, colonialista, capitalista e patriarcal. Concordamos que não há, porém, a necessidade de privarmo-nos dessas experiências e de todas as propostas ciborguianas delas derivadas, mas cabe aos "outros" [nós, da literatura menor (Deleuze e Guattari, 2003)] disputar visões de mundo, nos reconhecendo como agentes potentes dentro de um contexto múltiplo e complexo e reconhecendo nos outros sujeitos tão pujantes quanto o que reconhecemos em nós.

Os autores que utilizamos nesta breve recapitulação de posicionamentos antropológicos e filosóficos são também influenciados por esta hegemonia epistemológica que criticamos. Alguns por serem homens, outrxs por serem do norte-global. Nós mesmas, pesquisadoras, escrevemos esta reflexão a partir de uma vivência que parte de privilégios que nos foram conferidos por sermos brancas e pequeno-burguesas. No entanto, é essencial que essas ideias tenham espaço na discussão hegemônica para que o processo inclua, a partir destes, também os pensadores do sul global, as mulheres, as minorias. Todas as narrativas falam da sua verdade, cabe a nós termos sensatez e responsabilidade na escolha de qual história queremos contar e com quem.

\section{O fazer design anthropology para experimentar outros mundos}

No campo de design, inicialmente a antropologia esteve associada à aplicação de metodologias etnográficas nas fases iniciais de projetos, como ferramenta de pesquisa sobre os usuários e consumidores. Em paralelo, observa-se um interesse crescente de algumas áreas de design em abordar de forma mais crítica as suas questões, a relação com os atores envolvidos nos projetos e a reflexão sobre o próprio papel profissional frente aos desafios sociais contemporâneos. Nesse sentido, a aproximação com a antropologia tem um caráter mais reflexivo e crítico sobre como nos posicionamos no mundo e nas relações com os outros, seja no âmbito da pesquisa acadêmica ou da prática profissional. No Laboratório de Design e Antropologia (LaDA/Esdi/Uerj), buscamos essa "atenção imanente" através da abordagem de design 
anthropology, campo híbrido de produção de conhecimento com práticas próprias de pesquisa, experimentais e improvisatórias, além de posicionamento intervencionista, na busca de um engajamento dialógico entre profissionais e cidadãos para a cocriação de alternativas possíveis para o presente e o futuro.

Esse encontro interdisciplinar vem também de um movimento da antropologia de sair de sua limitação antropocêntrica e se abrir ao mundo da natureza e às questões concretas da vida, sem separar categoricamente os seres humanos desse todo mais complexo. Uma antropologia com ou por meio do design seria "uma antropologia entendida como modo inquisitivo de estar no mundo, em que o compromisso com a observação e a descrição esteja conjugado a um engajamento propositivo no sentido de uma transformação desse mesmo mundo" (Anastassakis, 2013, p.182).

Neste sentido, é importante entender que Ingold (2016) reconhece o propósito da antropologia como a educação da atenção, e não o mero relato etnográfico como resultado de uma prática antropológica. $\mathrm{O}$ autor reconhece que a prática antropológica é, no limite, uma percepção das práticas sociais cotidianas do encontro e da observação (participante). O participar aí seria o encontro com, através do qual a vida transborda. Ingold (2016, p. 407) nos coloca a questão: "Como compatibilizar o engajamento da participação com o distanciamento da observação?”, a qual ele mesmo responde: não há formas de separar o estar no mundo e o conhecer o mundo, é impossível desejar a verdade sobre o mundo através de um desligamento. Conhecer é estar presente. Assim, ressalta Ingold, “a observação participante não é, em absoluto, uma técnica à paisana para coleta de informações das pessoas, sob o pretexto de estar aprendendo com elas. É, antes, a contemplação, em ato e palavra, daquilo que se deve ao mundo pelo próprio desenvolvimento e formação" (ibidem, p. 407). Isso é o que ele chama de compromisso ontológico.

Não pode haver encontro ou observação sem participação - ou seja, sem uma composição íntima e sem ação entre observador e observado. Ingold propõe o termo correspondência para compreender esse arranjo de movimentos que, à medida em que se desenrolam, respondem continuamente uns aos outros (Ingold, 2016). Não significa, no entanto, nada relativo à representação ou descrição de alguma observação ou de alguma prática. Tem-se uma resposta intervencionista, um jogo de perguntas e respostas em um viver atencional, ao contrário de intencionalmente, com e para os outros.

Fazer-se um observador participante é estar em correspondência com aqueles com quem se quer aprender ou entre os quais há interesse de 
compreensão. É um movimento que, ao invés de recuperar o passado, almeja um futuro conjunto. Foge-se, portanto, dos objetivos descritivos e documentais atrelados historicamente à antropologia quando se determina como própria finalidade a trajetória de aprendizado e quando se propõe a “coleta de dados" como exercícios de estar com (Ingold, 2016).

Aliando essas considerações à nossa vivência enquanto designers, compreendemos nossa prática antropológica como projetual, uma vez que atuamos atencionalmente, modificando encontros e desenvolvendo nossa observação e participação a partir disso; ou, como sugere Tim Ingold, uma antropologia com ou por meio do design, em que o conhecimento é contextualizado, situado e engajado, em um processo de movimento e ação reflexiva, em correspondência às dinâmicas de crescimento e transformação das pessoas envolvidas (Ingold, 2013; Gatt e Ingold, 2013).

Para explorar o estar no mundo e o fazer com outros, utilizamos o potencial das ferramentas de design para materializar o intangível, posicionando dispositivos - objetos, imagens, sistemas e dinâmicas - como facilitadores de reflexões e engajamento, sem propor soluções para questões de pesquisa, mas, pelo contrário, encontrando formas de estar junto à questão e enxergá-la de novas formas (Olander, 2014; Binder et al., 2011).

Recordamos aqui que nosso desejo não é propor algo centrado na nossa visão de mundo, onde outros são consultados para validar nossa própria intenção. Efetivamente, o que almejamos é o contrário, para evidenciar as pontes entre os discursos e visões de mundo, construímos ferramentas de diálogo que deslocam o papel do protótipo do lugar de rascunho, algo que se refina até chegar em uma versão finalizada, para o lugar central de ferramenta facilitadora de participação (Halse et al., 2010; Donovan et al., 2012). Aliando isso à noção de "provótipo", exploramos o conceito de "dispositivos de conversação": artefatos e peças gráficas experimentais que facilitam o engajamento e o diálogo em torno de determinada questão, e cuja função primária e central é "mediar conversações e provocar a imaginação" (Anastassakis \& Szaniecki, 2016).

Alinhada com este pensamento e na perspectiva da construção de narrativas combativas, Elizabeth Tunstall propõe utilizar o que reconhece como uma metodologia de design anthropology para construir processos descolonizados no engajamento entre design e antropologia. Contextualiza a necessidade de descolonizar a antropologia (Harrison, 1991, apud Tunstall, 2013), desmistificar ideologias hegemônicas e co-produzir formas de conhecimento que possam ser úteis e potencialmente libertadoras, desassociadas dos projetos de colonialismo e imperialismo (Tunstall, 2013). Neste sentido, a autora critica as abordagens sociais do design voltadas para 
um modelo hegemônico de inovação, baseado em paradigmas ocidentais de pensamento linear e racional, distantes dos contextos das comunidades em que buscam atuar. Apresentando design anthropology como uma metodologia potencialmente descolonizada para o engajamento com questões sociais, ela entende que este explora os processos e artefatos do design na busca de um entendimento profundo da natureza humana e da tradução de valores em experiências tangíveis. Tais sistema de métodos, princípios e regras, com atenção às tendências colonialistas, contribui para a autodefinição daqueles anteriormente colonizados e permite parar o processo quando a ética do engajamento for questionada.

Dessa forma, design anthropology, como uma terceira via de conjunção entre design e antropologia, também se relaciona ao fazer e pensar do design político, na medida em que busca criar espaços de disputa e diferença, além de atuar para a investigação sobre a condição política (DiSalvo, 2010). De acordo com Carl DiSalvo, o design político se diferencia do design para a política (que apoia mecanismos de governança através de produtos e serviços), ao buscar contribuir para a ampliação de uma democracia agonística, não hegemônica e consensual, mas baseada no conflito e disputa entre ideais, valores e crenças concorrentes. O "design antagonista" (adversarial design, no original) encoraja a contestação e o dissenso através de ambientes projetados para apoiar o reconhecimento de questões, discursos e práticas, revelar e confrontar relações de poder e possibilitar reivindicações e argumentos contestatórios (DiSalvo, 2015). O potencial democrático da participação em processos de design pode ser explorado através métodos, ferramentas e técnicas de engajamento próprias desta forma outra de pensar e fazer. Por meio de atividades de visualização, imaginação, experimentação e reflexão contínua, o design pode assumir um papel importante na democratização da democracia, preparando as condições necessárias para que questões controversas emerjam e possam ser discutidas de modo amplo e democrático (Binder et al., 2015).

\section{Práticas acadêmicas: encontros e movimentos do eu e do outro}

Inseridas no LaDA, apresentamos aqui duas pesquisas em desenvolvimento inicial no âmbito dos estudos doutorais, em que buscamos atuar em correspondência à realidade e engajadas com as pessoas envolvidas, em um processo aberto de investigação colaborativa por meio do design. Através de ferramentas mediadoras que provoquem diálogos, realizamos experimentos para o questionamento e a criação de novas questões em campo na relação 
com os outros, evitando a postura de achar que os problemas são conhecidos de antemão.

"Rio Comprido em Nós" é um projeto iniciado durante o mestrado da pesquisadora Mariana Costard e ainda em desenvolvimento durante seu doutorado. Explora o design como modo de investigação coletiva sobre a cidade entre diversas dimensões e perspectivas, utilizando suas ferramentas e métodos para provocar diálogos sobre questões de interesse comum e possíveis construções colaborativas. Com trabalho de campo localizado no bairro do Rio Comprido, Rio de Janeiro, tem atuação engajada com a comunidade envolvente desde 2014, utilizando ferramentas mediadoras para provocar o diálogo, a reflexão crítica e a imaginação coletiva sobre as questões locais e alternativas possíveis, em alinhamento às teorias e práticas de design anthropology.

Em contexto urbano, Costard atua localmente com diferentes grupos sociais que vivem o território, pretendendo-se co-pesquisadora junto à comunidade, em entendimento de que a própria faz o desenho de si mesma através de suas práticas cotidianas. Atualmente, a pesquisadora tem participado de ações de um coletivo atuante no bairro, com a intenção de acompanhar suas interferências "de fora" e contribuir para um diálogo mais aberto com as pessoas, pensando como aumentar essa participação local em projetos que visam uma escala mais sistêmica e estratégica. Também tem desenvolvido um projeto em parceria com o Cap-Uerj, uma escola da rede pública que é parte da Universidade do Estado do Rio de Janeiro (Uerj). Nesse caso, a investigação colaborativa com as crianças visa uma troca entre perspectivas diversas, através de ferramentas e métodos do design, como cartografias, jogos e atividades de visualização e imaginação. Segundo Ingold (2017), as crianças (assim como os povos tradicionais e outras minorias) são consideradas dominadas em suas visões de mundo na opressora disputa pelo conhecimento e podem contribuir para se pensar essa ciência "menor", em oposição às práticas institucionalizadas e hegemônicas que temos discutido neste artigo.

A pesquisa busca também a prática de um design político (DiSalvo, 2010) que estimule espaços de disputa e multiplicidades de opiniões e desejos, que contribua para ampliar a participação e democracia no processo de construção das cidades. Explora o potencial democrático do co-design (Binder et al., 2015) de fazer conexões sócio-materiais que envolvam designers e não designers, além de profissionais de outras áreas disciplinares, para a criação coletiva através de ferramentas e técnicas experimentais. Tem interesse na melhoria do bairro, porém alinhada com um design autônomo (Escobar, 2016) que questione os parâmetros de desenvolvimento e 
revitalização urbana a partir de uma prática local, trabalhando a gestão dos bens comuns como micropolíticas, mas também em conexão com uma perspectiva mais sistêmica e estratégica, buscando tensionar o planejamento urbano e a formulação de políticas públicas.

Outra prática situada que desejamos apresentar é o projeto de doutorado de Bibiana Oliveira Serpa, que se desenha no âmbito do ativismo político da pesquisadora no movimento feminista do Rio de Janeiro. Aliando experiências da militância com reflexões acerca de novas práticas de design politicamente conscientes e engajadas, o projeto associa preceitos da educação popular e de design anthropology para explorar novas formas de produzir e socializar conhecimentos. O trabalho teve início junto a uma formação feminista co-liderada pela pesquisadora. Em parceria com a estudante de graduação Clara Juliano e as gestoras da coletiva proponente da formação, foram desenvolvidos dispositivos de conversação (Anastassakis \& Szaniecki, 2016) com objetivo de mediar discussões pautadas tanto na ementa do curso quanto nas experiências das participantes, questão primordial para a educação popular.

Pautados pelo intervencionismo inerente às práticas de design anthropology, que propõe um envolvimento prático com os sujeitos e os contextos de pesquisa, a elaboração das dinâmicas e os momentos de encontro quando elas são colocadas em xeque são espaços orgânicos que influenciam um ao outro, guiando e alimentando a pesquisa e as agentes através de reflexões das pesquisadoras e do restante do coletivo (Binder et al., 2011). Estas atividades não buscam estabelecer verdades absolutas ou soluções finais tanto em termos conceituais-educativos feministas quanto no objeto de design co-criado. A intenção é mediar o debate e a coexistência de subjetividades distintas, convergentes ou divergentes, tornando-as tangíveis, através do processo de produção coletiva dos dispositivos pelas gestoras, pesquisadoras e educandas, na ciência de que há alteridades e disputas em jogo. O interesse da investigação, portanto, se configura não em seguir à risca a proposta inicialmente formulada em cada dinâmica, muito menos em obter resultados específicos ou esperados, mas, sim, em educar a atenção para a complexidade de agentes, interesses e fatores que compõem o processo e entender esses elementos que tensionam as práticas como fundamentais - e, acima de tudo, reais (Ingold, 2016). Ao provocar reflexões sobre assuntos latentes, os encontros (Ingold, 2016) não têm como objetivo prover respostas, soluções ou argumentos finais (Brand et al., 2011), mas propõem questões emergentes que dizem respeito à proposta de disrupção com o modelo hegemônico, descentralizando a fala, o posicionamento e pautando um posicionamento político agonístico (DiSalvo, 2010) e em disputa. 
Ser uma ativista envolve frequentemente abordar um conjunto de práticas simultaneamente para alcançar um conjunto abrangente de metas, para mobilizar mais e se envolver em atividades em constante movimento. $\mathrm{O}$ vínculo entre design e as movimentações sociais como uma força geradora de saberes é uma oportunidade de promover novas práticas no interior do movimento e propor novas formas de ver e fazer design, da mesma forma que são potencializadas novas formas de ser e fazer feminismo. Deste modo, o design não é mais um apoiador final no desenvolvimento de produtos que representam e apresentam o movimento (na forma de materiais gráficos, produtos para venda, etc), mas pode cumprir um papel propulsor do próprio ativismo, centrando sua ação no desenvolvimento dos processos do movimento social, alavancando a imaginação coletiva de dentro da articulação do movimento social com design.

Essas são experiências de atuação que têm como horizonte o deslocamento das investigadoras e um novo posicionamento frente às questões do design e da pesquisa em design. O campo Design Anthropology, como área em turbulência, instável e em constante movimento, permite que atuemos de forma exploratória e improvisatória, sempre buscando uma coresponsabilidade projetual com todos que embarcam nesta experiência relacional.

\section{Design para muitos mundos possíveis}

Tendo delineadas as referências teóricas em que nos baseamos e as abordagens de design que influenciam e tensionam a nossa reflexão e prática, propomos aqui a busca de design(s) para muitos mundos possíveis, a partir de uma perspectiva do sul global, que vai ao encontro da proposta de Arturo Escobar do design para o pluriverso.

Queremos nos colocar em movimento e propomos que essa movimentação seja realizada com atenção e cuidado. Esse cuidado, no entanto, não deriva do medo, mas da disposição para com o eu e o outro. Stengers (2017) já anunciou que as realizações científicas são advindas da aventura, do desejo de estar no mundo e descobrir-se enquanto parte. Elas não são, portanto, voltadas à conquista deste mundo, como propõe a Ciência.

A aventura de se fazer ciência contra-hegemônica, aquela nãopatriarcal, não-capitalista, não-colonizadora, não-classista, possibilita experimentos improvisados e compromissados com as perguntas, não com as respostas. Essa postura nos coloca em risco, a mudança como forma ativa de criação é uma experiência poderosa, ainda que perigosa. Mas essa é a postura que desejamos alcançar junto aos antropólogos, aqueles que não devem "nem explicar, nem interpretar: multiplicar” (Viveiros de Castro, 2002: 129). 
Reconhecendo o terreno complexo, entendemos que as narrativas não estão em disputa com objetivo a um final. As divergências de pensamentos, tanto em âmbito macro (da colonização, do capitalismo, do patriarcado) quanto em âmbito micro (nas atuações cotidianas e situadas), são presenças nos debates e esse por si só é o discurso, o do dissenso e do reconhecimento de outros (Strathern, 2006).

Tomando a questão de Ingold (2016) de que a prática antropológica é, no limite, uma interpretação das práticas sociais do encontro e da observação participante, reconhecemos que nossa prática, que não é antropológica, mas conjugada entre design e antropologia, de inferência, é a tradução prática do entendimento do dissenso como fundamental para encontros fecundos rumo à essa proposta de outros mundos. Ao desmistificar ideologias hegemônicas e co-produzir formas de conhecimento que possam ser úteis e potencialmente libertadoras, desassociadas dos projetos de colonialismo e imperialismo, criticamos, com apoio de Tunstall (2013), as formas hegemônicas que abordam socialmente design na perspectiva cartesiana e totalizante, quando se tem a intenção previamente colocada e não a atenção às situações, que colocam tudo em constante movimento e construção.

A prática e teoria de design anthropology vêm no intuito de propor novas formas de acessar essas questões de interesse social do design. A realidade pretendida, então, é forjada a partir das diferentes identidades evocadas e tem o design como ferramenta engajadora, ao contrário de propositora, que desafia forças dominantes, estabelecendo novas formas de diálogo, através da emergência de questões e formação de públicos (DiSalvo, 2010). Essa proposta nos convida a enfrentar e propor experimentalmente outra realidade, o que cria condições para ação colaborativa e mudanças coletivas (Bjorguinsson et al., 2010).

Na tentativa de propor esses encontros (Ingold, 2016) e formular essas outras mesmas realidades, situamos nossos trabalhos doutorais em desenvolvimento junto ao LaDA. O trabalho com espaços urbanos, articulando diferentes agentes em torno de questões de interesse comum e possíveis construções colaborativas; bem como a pesquisa desenvolvida junto ao movimento feminista e a formação política das sujeitas deste movimento de forma agonística, aproximam-se do design político (DiSalvo, 2010; 2015) e engajado e propõem novas formas de reconhecer e fazer design.

Neste sentido, compreendemos que se deixar permear pelos pensamentos e práticas outras é reconhecer o poder de criar pontes, e dar às ideias do passado o poder de afetar o presente (Stengers, 2017) e o futuro. Nesse sentido, delineia-se uma contradição. O problema não está em colocar 
o outro (o 'nativo', o pesquisado) como objeto, e nem a solução é entendê-lo como sujeito igual. O outro certamente pensa, como o eu; mas, muito provavelmente, ele não pensa como o eu. A pretensão ao conhecimento implícita no discurso do outro no eu é um problema epistemológico, político. Não é possível incorporar o processo de dominação do outro e vislumbrar novas possibilidades de ação e reflexão pelo simples fato de compreender as distorções de poder e estar ciente e sensível a elas. Reconhecemos a controvérsia entre a assunção das identidades distintas e a potencialidade das relações e conexões criadas entre esses agentes. Como mostra o apanhado teórico exposto aqui, os encontros e as proposições a partir deles direcionam a nossa atencionalidade ao mesmo tempo em que reconhecemos os indivíduos relacionais.

Quando nos colocamos nesta perspectiva, aceitamos que existem "lados" e visões privilegiadas. Essas questões não somem porque tomamos consciência delas. As narrativas, as metodologias e o estar no mundo estão em disputa. Nossa própria existência está em disputa. Ao nos propormos a fazer um design com ao invés de um design para, a pensar uma ciência menor ao invés da Ciência, a narrar uma história não-hegemônica ao invés da que está consolidada, nos colocamos em risco. O risco iminente de pisar do lado errado da linha, de perder o rumo na curva. Assumimos esse risco, e é aí que mora nosso desafio e nossa potência.

\section{Referências}

ACOSTA, Alberto. O bem Viver - Uma oportunidade para imaginar outros mundos. São Paulo: Elefante, 2016.

ANASTASSAKIS, Zoy. Laboratório de Design e Antropologia: preâmbulos teóricos e práticos. In: Arcos Design. Rio de Janeiro: PPD ESDI UERJ. Volume 7 Número 1. pp. 178-193. Junho, 2013.

ANASTASSAKIS, Zoy; SZANIECKI, Barbara. Conversation dispositifs: towards a transdisciplinary design anthropological approach. In Design Anthropological Futures. Bloomsbury Academic, 2016.

BINDER, Thomas, et al. Design Things. The MIT Press, 2011.

BINDER, Thomas, et al. Democratic design experiments: between parliament and laboratory. CoDesign 11.3-4: 152-165, 2015.

BJÖGVINSSON, et al. Participatory design and democratizising innovation. Proceedings of PDC. Sydney, Australia, 2010.

BRANDT, E.; REDSTRÖM, J.; ERIKSEN, M. A.; BINDER, T. XLAB. The Danish Design School Press, 2011. 
DELEUZE, G.; GUATTARI, F. Kafka: Para uma literatura menor. Tradução Rafael Godinho. Lisboa: Assírio \& Alvim, 2003.

DISALVO, Carl. Design, democracy and agonistic pluralism. Proceedings of the design research society conference. 2010.

DISALVO, Carl. Adversarial Design. Cambridge e Londres: The MIT Press, 2015.

ESCOBAR, Arturo. Autonomia y diseño - la realización del comunal. Buenos Aires: Tinta Limon, 2017.

GATT, Caroline; INGOLD, Tim. From description to Correspondence: Anthropology in Real Time. In: Design Anthropology: Theorie and Practice. Ed: Gunn, Wendy; Otto, Ton; Smith, Rachel. p. 175-198. Bloosmbury, 2013.

GUNN, Wendy; DONOVAN, Jared. (Eds.) Design and Anthropology: Anthropological studies of creativity and perception. London: Ashgate, 2012.

HARAWAY, Donna et al. Antropologia do ciborgue: as vertigens do póshumano. Belo Horizonte: Autêntica, 2009 [1985].

INGOLD, Tim. Making: Anthropology, Archaeology, Art and Architecture. Abingdon: Routledge, 2013.

INGOLD, Tim. Chega de etnografia! A educação da atenção como propósito da antropologia. Revista Educação. Porto Alegre, v. 39, n. 3, p. 404-411, set.-dez. 2016.

INGOLD, Tim. Anthropology and/as Education. Routledge, 2017.

STENGERS, Isabelle. Reativar o animismo, in Caderno de leituras n.62. Tradução Jamille Pinheiro Dias. Chão da Feira, [2012] 2017.

STRATHERN, Marilyn. O gênero da dádiva. Problemas com as mulheres e problemas com a sociedade na Melanésia. Campinas, Editora da Unicamp, 2006.

TUNSTALL, Elizabeth. Decolonizing design innovation: design anthropology, critical anthropology, and indigenous knowledge. In: Design anthropology: theory and practice, p. 232-250, 2013.

VIVEIROS DE CASTRO, Eduardo. O nativo relativo. Mana 8.1: 113-148, 2002.

WAGNER, Roy. A invenção da cultura. Ubu Editora, [1975] 2017. 


\section{Como citar}

SERPA, Bibiana; Costard, Mariana. Design Anthropology para muitos mundos possíveis. Arcos Design. Rio de Janeiro: PPD ESDI - UERJ. Volume 11 Número 2 Dezembro 2018. pp. 7-25. Disponível em: [http://www.e-publicacoes.uerj.br/index.php/arcosdesign]

DOI: $10.12957 /$ arcosdesign.2018.47515

\section{(C) (1) $\Theta(0$}

A Revista Arcos Design está licenciada sob uma licença Creative Commons Atribuição - Não Comercial - Compartilha Igual 3.0 Não Adaptada. 